\title{
AS ONDAS DO FEMINISMO E SEU IMPACTO NO MERCADO DE TRABALHO DA MULHER
}

THE WAVES OF FEMINISM AND ITS IMPACT ON WOMEN'S LABOR MARKET

Carolina Bastos de Siqueira Doutora/Faculdade de Direito de Vitória carolbastos@msn.com

Elda Coelho de Azevedo Bussinguer Doutora/Faculdade de Direito de Vitória elda@fdv.br

\begin{abstract}
Resumo: Este artigo analisa as mudanças que se operaram no processo de inserção da mulher no mercado de trabalho brasileiro, a partir das ondas do feminismo, desde sua aurora liberal, até a percepção atual do feminismo pós-estruturalista. Visa identificar as ondas do feminismo e seus objetos de estudo/reivindicações, correlacionando com a inserção da mulher no mercado de trabalho, e analisar qual o impacto, se é que houve, das ondas do feminismo, em suas diferentes matrizes, no mercado de trabalho da mulher. Recorre-se à matriz metodológica do materialismo histórico-dialético, pois confronta as teorias feministas, no plano do ideal, com os fatos ocorridos na história. Conclui-se que, apesar da profunda mudança no mercado de trabalho, esta tem relação mais próxima com as alterações perpetuadas pelo capitalismo com os ideais neoliberais e não está propriamente conectada com o movimento feminista.
\end{abstract}

Palavras-chave: Movimento feminista. Mercado de trabalho da mulher. Trabalho feminino.

Abstract: This article analyzes the changes caused by women insertion into Brazilian labor market throughout the feminism waves. It aims to identify these waves and its subjects of study/claims such as their impacts - if any - on women's labor market. This study relies on the methodological approach of the historical-dialectical materialism, since it confronts feminist theories on the ideal plan with historical facts. It follows that the profound change of the labor market is due to the actions perpetuated by capitalism's neoliberal ideals and it is not directly related to the feminist movement.

Keywords: Feminist movement. Female labor market. Female labor.

SIQUEIRA, Carolina Bastos de; BUSSINGUER, Elda Coelho de Azevedo. As ondas do feminismo e seu impacto no mercado de trabalho da mulher. Revista Thesis Juris - RTJ, São Paulo, v. 9, n. 1, p. 145-166, jan./jun. 2020. http://doi.org/10.5585/rtj.v9i1.14977. 


\section{Introdução}

O feminismo, propriamente dito, surge sob o prisma das ideias de liberdade e igualdade relacionadas aos indivíduos no século XIX, especialmente em função dos ideais da Revolução Francesa que passaram a garantir aos homens uma série de direitos até então inimagináveis e, a partir desses conceitos, muitas fendas sociais foram questionadas e situações já cristalizadas foram perdendo seu aspecto natural.

Após a conquista dos homens de mais liberdade em relação ao Estado e da difusão das ideias de igualdade, o processo de questionamento da realidade por mulheres, trabalhadores e outros grupos minoritários encontrou terreno fértil para se desenvolver, apesar do fato de que, desde a antiguidade, já houve diversas mulheres que questionaram seu papel pré-estabelecido e que viveram de acordo com regras próprias.

O papel das mulheres, culturalmente, aceito, até então, era aquele que as restringia ao espaço privado e as condicionava ao papel de etnias "inferiores", uma vez que deveria servir às etnias "superiores". Escravidão, misoginia, exploração das classes subalternas, todas essas opressões ganharam contornos diferenciados a partir da nova óptica estabelecida. Se todos são iguais e livres, não há razões para que mulheres, negros, pobres ou qualquer outra minoria sofra ou seja oprimida e explorada tão fortemente.

No entanto, este é um processo lento e gradativo, uma vez que mudanças não ocorrem suavemente e sem consequências. Elas são sentidas fortemente, marcando os envolvidos de forma muitas vezes drástica, já que poder e espaço não são cedidos sem resistência e luta.

O processo de libertação é, portanto, sempre acompanhado de dor, de dúvidas e de inseguranças, já que quem sofre opressão não se reconhece facilmente na posição de um igual e, quando o faz, não costuma encontrar uma receptividade calorosa.

Desde os ideais da Revolução Francesa consubstanciados na Declaração dos Direitos do Homem em que se reconhece ao ser humano o direito à liberdade, à igualdade e à fraternidade. No entanto, mais de 200 anos se passaram e ainda persistem situações de desigualdade, de opressão e de injustiças espalhadas, ainda que de forma desigual, por todas as partes do planeta.

Situações de violência contra a mulher, de opressão aos trabalhadores, de preconceito com povos de etnias minoritárias, de manutenção da mulher no espaço privado e nas relações de trabalho reprodutivo permanecem presentes, no cotidiano, e fincadas fortemente na cultura. À luz desse cenário, a humanidade ainda precisa de muito tempo para ser realmente igual e 
livre, para que, em algum momento no futuro, os seres humanos não sejam mais separados e julgados por suas diferenças, mas conectados por suas semelhanças e proximidade.

Inegáveis, entretanto, os avanços e as conquistas alcançadas desde o período revolucionário francês. Uma análise mais direcionada ao caso das mulheres e da misoginia permite identificar sinais de mudança. A cada onda do feminismo, a cada inserção de uma nova perspectiva ao movimento feminista, as mulheres puderam, lentamente, ocupar algum lugar no espaço público.

No entanto, ainda que se reconheçam os avanços obtidos como resultado da luta empreendida pelas mulheres, a consolidação da igualdade está longe de ser materializada. Neste sentido, o presente estudo analisa, sob a óptica do trabalho, quais foram as mudanças que operaram no processo de inserção da mulher no mercado de trabalho brasileiro, a partir das ondas do feminismo, desde a sua aurora liberal, até a percepção atual do feminismo pósestruturalista.

Busca-se, assim, identificar as ondas do feminismo e seus objetos de estudo/reivindicações, correlacionando com a inserção da mulher no mercado de trabalho desde o surgimento do movimento feminista. Do mesmo modo, visa analisar, criticamente, qual teria sido o impacto, se é que houve, das ondas do feminismo, em suas diferentes matrizes, no mercado de trabalho da mulher.

Para responder o questionamento acerca dos impactos das diferentes ondas do feminismo no mercado de trabalho da mulher, a partir de uma matriz teórica e metodológica do materialismo histórico-dialético, busca-se, portanto, confrontar as teorias feministas, no plano do ideal, com os fatos ocorridos no decorrer da história, na realidade observada, com o fim de proceder a uma análise crítica dos impactos reais do movimento feminista.

\section{As ondas do feminismo}

A expressão “ondas do feminismo" é utilizada, neste trabalho, em caráter meramente didático, tendo em vista a necessidade de situar o leitor em uma perspectiva histórica que lhe permitirá acompanhar a evolução do fenômeno feminismo.

Na realidade, a expressão, apesar de ajudar na compreensão do fenômeno, parece remeter à ideia de movimento finito e sedimentado que pode levar a um equívoco no que diz respeito a tudo aquilo que a expressão representa.

Em virtude disso, é necessário trazer luz para uma ideia equivocada de finitude dos diversos movimentos feministas na história, como se a cada novo movimento que se inicia, a 
"onda" anterior estivesse a dissipar assim que atinge a praia - o que não é verdade. De fato, os diversos feminismos continuam a conviver, ainda que não de maneira harmoniosa no cenário acadêmico e social.

Em razão da conveniência didática, já explicitada, apresentamos as quatro ondas do feminismo hoje consideradas: a primeira relaciona-se com os direitos civis como voto, educação e até mesmo direito ao trabalho; a segunda está mais focada nos direitos reprodutivos e na sexualidade; a terceira está ligada ao pós-estruturalismo e a quarta tem suas raízes na difusão do tema dentro das redes sociais. Esta última ainda está em fase bem inicial e limitarnos-emos a mencioná-la tão somente, uma vez que a literatura sobre o tema até agora é bastante incipiente, não havendo ainda consolidado teórico.

O movimento feminista nasce no século XVIII (ALVES; PITANGUY, 1985, p. 32), partindo de uma perspectiva que cuida de retirar a mulher do espaço de opressão e de exclusão para colocá-la em uma posição que não a inferiorize perante seus iguais, pertencentes ao sexo masculino. Em outros termos, seu principal escopo seria o de excluir a categoria gênero dos espaços opressivos e tornar homens e mulheres, materialmente, iguais.

No entanto, esta concepção genérica não é, por si só, suficiente para descrever todo o fenômeno do movimento feminista. No decorrer da história, foram muitos feminismos e muitas perspectivas diferentes, que, de certa forma, se completam e, eventualmente, se contradizem, em busca da redução da desigualdade entre os gêneros.

É importante mencionar que, nesse campo de estudo, nenhum conceito é estanque. Existem várias concepções de feminismo, patriarcado, mulher, gênero e essas se constroem e se reconstroem no tempo e na história. No entanto, para que pudéssemos partir de um conceito de feminismo cuja premissa pudesse sustentar as reflexões a serem realizadas, no âmbito deste artigo, apropriamo-nos do pensamento de Gonçalves e Pinto (2011, p. 29) que afirmam que "a luta feminista se apóia $[\mathrm{sic}]$ no reconhecimento de que as mulheres são oprimidas específica e sistematicamente e que essa opressão não está inscrita na natureza".

Em outras palavras, o feminismo questiona o papel atribuído à mulher na sociedade como naturalmente inferior ao homem e limitada ao espaço privado, colocando em xeque as características ditas femininas relativas à passividade, ao cuidado e à domesticidade como um todo.

Segundo Friderich Engels (1981, p. 22), a mulher foi a primeira a sofrer opressão, muito antes da existência da classe trabalhadora. Em suas palavras, "o primeiro antagonismo de classe que apareceu na história coincide com o desenvolvimento do antagonismo entre o homem e a mulher". Retomaremos a esta fala ao analisarmos a primeira fase do movimento feminista. 
Para compreender este fenômeno, é fundamental que reconheçamos também "algumas características do feminismo enquanto movimento político coletivo, internacional, não unívoco e multifacetado" (GONÇALVES; PINTO, 2011, p. 29), ou seja, ainda que possamos perceber nuanças diferentes e marcos temporais desconexos no Brasil e em diversos outros países, o movimento sempre caminhou no sentido de combater o patriarcado e diminuir a opressão das mulheres.

O feminismo da chamada "primeira onda" buscou a inserção da mulher no processo político e decisório das sociedades às quais pertenciam. Esse movimento que era, essencialmente, de mulheres brancas pertencentes à classe média e relacionadas com a intelectualidade, foi mais comum em países economicamente mais desenvolvidos (NARVAZ; KOLLER, 2006, p. 648).

Ele se inicia a partir da Revolução Francesa, na medida em que as mulheres que tomaram parte no processo revolucionário da época puderam perceber que não haviam conquistado uma emancipação no tocante às suas próprias opressões, isto é, não lhes foram estendidos os direitos de cidadania pelos quais lutaram ao lado dos homens (ALVES; PITANGUY, 1985, p. 32).

Os ideais democráticos e de construção da cidadania estavam em franco desenvolvimento e as mulheres que colaboravam na luta pelos direitos de liberdade, de igualdade e de fraternidade para todo o povo, também buscavam esse reconhecimento para seu gênero. Essas ideias não ficaram adstritas à França, já que, pouco tempo depois, estavam disseminadas em diversos países da Europa e, em especial, na Inglaterra, com a publicação do livro "Reivindicações dos direitos das mulheres”, de Mary Wollstoncraft, em 1792 (2016).

Ao se avaliar a perspectiva atual, pode-se dizer que este início do movimento buscava retirar a mulher do espaço privado e incluí-la no espaço público, inicialmente, lutando pelo direito de frequentar a escola e votar.

Alguns autores afirmam que essa primeira onda poderia ser considerada um feminismo liberal, que buscava conceder à mulher, liberdades civis como os direitos ao voto e à educação que lhes era negado e que os homens já haviam conquistado, como bem evidencia Narvaz e Koller (2006, p. 649), tendo sido essa a primeira percepção e luta feminina pelo espaço público.

Esse movimento, em determinado momento, aproxima-se das mulheres da América Latina, cujas lutas, em comparação com alguns países europeus, iniciaram-se anteriormente. Segundo Maria Amélia de Almeida Teles (1999, p. 40), as mulheres do Chile, em 1876, ao perceberem uma falha em sua Constituição Republicana que não proibia diretamente o voto 
feminino, lutaram por seus direitos políticos, tendo sido um dos primeiros movimentos do gênero entre os latino-americanos.

No contexto brasileiro, seu aparecimento se dá incialmente por meio de mulheres como Nísia Floresta Brasileira Augusta, que, ao traduzir a obra da inglesa Mary Wollstonecraft, já mencionada, introduziu os ideais do feminismo no Brasil e contribuiu para a luta pelo acesso feminino ao direito de estudar e de trabalhar (DUARTE, 2003).

Contudo, a mesma ressalva quanto ao grupo social abarcado por esses movimentos se faz no Brasil assim como se fazia na Europa, esse início do movimento atingia mais fortemente a mulher proveniente das classes mais favorecidas e não tinham tanto reflexo na vida da mulher operária.

Posteriormente, no ambiente do trabalho, houve a eclosão de diversos movimentos grevistas nos quais a presença feminina era massiva, ainda que atingissem poucas conquistas em comparação a seus companheiros homens. Foram as mulheres operárias, portanto, que deram maior organização ao movimento feminista no Brasil, especialmente na busca pela regulamentação do trabalho feminino (TELES, 1999, p. 42).

Zuleika Alvin (1983, p. 78) ressalta a grande importância da participação feminina nos movimentos grevistas do início dos anos 1900s, ressaltando, inclusive, algum protagonismo delas em greves gerais e o aparecimento das primeiras pautas que incluíam questões relacionadas ao gênero, com reivindicações relacionadas à equiparação salarial, por exemplo.

A partir do século XX, a "primeira onda" brasileira também passa a ser pautada nas mulheres de classe social privilegiada e seu ponto nevrálgico, assim como no feminismo que se desenvolveu no resto do ocidente, foi a ocupação feminina do espaço público, com a luta pelo direito ao voto e ao trabalho que se intensifica a partir de 1910, com a fundação do Partido Feminino Republicano, que defendia o preenchimento dos cargos eletivos por pessoas de quaisquer sexos.

Em 1920, Bertha Lutz organizou a Federação Brasileira pelo Progresso Feminino, que buscava inserir a mulher no processo educacional, garantir o direito à maternidade especialmente para a mulher trabalhadora, propiciar formação técnica para sua inserção no mercado de trabalho, buscar a integração feminina, direitos de cidadania e a internacionalização do movimento feminista na América (TELES, 1999, p. 43-44).

Passadas as duas Grandes Guerras, segundo Nancy Fraser (2016, p. 37-38), o contexto social é alterado com a inserção do "Estado de Bem-estar Social" e do capitalismo que passaria a ser organizado pelo Estado, o que trouxe uma grande alteração na percepção do Estado para 
a inclusão de categorias menos valorizadas até então, especialmente a classe trabalhadora, porém seu foco inicial foi a inserção do que se poderia chamar de "chefe e homem de família".

Retomando, portanto, a lição de Engels (1981, p. 22), que afirmou ser a mulher a primeira classe oprimida, enquanto a classe trabalhadora inicia um processo de luta por direitos sociais e passa a vê-los garantidos pelo Estado, a situação feminina não sofre maiores alterações, já que as trabalhadoras do sexo feminino continuam a sofrer discriminação por sua condição de inferior.

Naquele período, a percepção central foi de valorização do salário do trabalhador homem, que tinha como "função precípua" a de macho provedor, enquanto quaisquer ganhos da mulher seriam considerados como mero complemento, ou melhor, valores extras que não iriam compor diretamente o sustento da família e esta ideia "serviu tanto como um ideal social, conotando modernidade e mobilidade ascendente, quanto à base para política estatal em matéria de emprego, bem-estar social e desenvolvimento" (FRASER, 2016, p. 38).

Portanto, ainda que a mulher tenha obtido avanços com alguma inserção no espaço público, o Estado de Bem-estar Social, resultante do pós-guerra, não cumpriu com o prometido, uma vez que "a cultura política do capitalismo organizado pelo Estado era economicista, androcêntrica, estatista e Westfaliana - características todas que foram objeto de ataque no final das décadas de 1960 e 1970" (FRASER, 2016, p. 39).

O movimento feminista, então, vai ganhando outras bandeiras, dando início à sua "segunda onda" e inserindo a busca por uma igualdade entre homens e mulheres e pela valorização de suas diferenças. A questão da igualdade está mais relacionada ao feminismo americano e a questão da valorização das diferenças refere-se mais comumente ao movimento francês (NARVAZ; KOLLER, 2006, p. 649).

Nesta fase, percebeu-se que a injustiça social não estaria adstrita à questão classista, uma vez que, além da classe, o gênero e a raça também estariam inseridos no processo de opressão de determinados grupos, uma vez que "as práticas sociais tinham impedido algumas pessoas de serem incluídas nessa categoria universal e buscava remover os obstáculos para a realização de seus direitos individuais" (SCOTT, 2005, p. 22).

Na visão de Fraser (2016, p. 39-40), a segunda onda do feminismo ultrapassou o conceito de injustiça relacionado à desigualdade social e buscou enfrentar um conceito de justiça mais amplificado, "rejeitando todo o foco exclusivo no Marxismo na economia política quanto o foco exclusivo no liberalismo na lei, elas desvendaram injustiças localizadas em outros lugares - na família e em tradições culturais, na sociedade civil e na vida cotidiana”. 
Não há, portanto, um objetivo único que se possa extrair desta segunda fase do movimento, já que suas premissas são um paradoxo, aparentemente, inconciliável, sobretudo quanto à inclusão de pautas outras que não estavam inseridas no movimento inicial por meio de ações afirmativas (SCOTT, 2005, p. 23).

Contudo, foi um período fundamental para o aparecimento das reivindicações das mulheres negras, pobres, ou seja, populações que não estavam tão assemelhadas ao grupo pertencente à primeira onda e que precisavam buscar acessos diferentes para que pudessem garantir igualdade.

A partir da década de 1970, a segunda onda do movimento chega ao Brasil, naturalmente com certo atraso, e as pautas desse segundo movimento, conforme dito alhures, relacionavamse com a igualdade entre mulher e homem no mercado de trabalho e no comportamento sexual. (TELES, 1993, p. 70-99)

Na década de 1980, no Brasil, as pautas da mulher negra também passam a integrar o movimento feminista (TELES, 1993, p. 92), buscando, a partir da percepção das diferenças no tocante às reivindicações das mulheres brancas e negras, políticas públicas que as considerassem, evitando, assim, que apenas a mulher branca, especialmente a pertencente às classes média e alta, tivesse seus direitos reconhecidos.

De fato, há um grande abismo entre as opressões desses grupos sociais com relação ao movimento feminista, porque a reivindicação pelo direito ao trabalho da mulher branca não se prestava a solucionar os problemas da mulher negra, já que esta sempre esteve no mercado de trabalho e atuava em cargos não valorizados na sociedade, portanto, sem reconhecimento financeiro expressivo.

No campo internacional, a partir da década de 80, iniciou-se um questionamento acerca de algumas verdades científicas, especialmente nas ciências sociais que, até então, se inspiravam nos modelos de pesquisa das ciências duras e biológicas, partindo para um processo de desconstrução com o pós-estruturalismo (NARVAZ; KÖLLER, 2006, p. 650).

Algumas certezas foram e ainda são questionadas, o conceito de verdade foi colocado em xeque, afinal, se todas as ideias e as relações são intermediadas pela linguagem e esta não é natural e biológica, apenas fruto de cada cultura, não se poderia olvidar da fragilidade que as verdades queiram impor.

Esta "crítica pós-modernista da ciência ocidental introduz o paradigma da incerteza no campo do conhecimento" e influencia, especialmente, o feminismo francês, a partir de Foucault e Derrida, buscando analisar os diversos espectros do ser humano como concebidos pela linguagem, em um processo “dialógico e intersubjetivo" (NARVAZ; KÖLLER, 2006, p. 649). 
Nasce, a partir desta perspectiva, a "terceira onda" do feminismo, que se dedica ao reconhecimento das "diferenças, da alteridade, da diversidade e da produção discursiva da subjetividade" e, portanto, mudando o foco central do feminismo, até então limitado às mulheres, para as chamadas "relações de gênero" (NARVAZ; KÖLLER, 2006, p. 649).

Foram inseridas, especialmente na academia, questões relativas à masculinidade, aos homossexuais, transexuais, bissexuais, assexuados, enfim, toda a Teoria Queer cuja maior expoente teórica é Judith Butler. A ideia de gênero, portanto, vem sendo completamente revisada neste período do movimento feminista, trazendo uma perspectiva mais fluida e incluindo outras minorias oprimidas não necessariamente mulheres, mas vítimas da mesma opressão imposta e/ou originada no patriarcado (SIQUEIRA; BUSSINGER, 2017).

Houve, portanto, uma revisão do foco no estudo das políticas inclusivas de gênero, uma vez que determinadas políticas direcionadas exclusivamente às mulheres não seriam suficientes para promover a igualdade entre os cidadãos. A perspectiva desta fase do movimento é a de que não há apenas homens e mulheres, divididos nesses dois grandes grupos por determinação biológica, mas toda uma gama de pessoas que não se encaixam nesse padrão pré-determinado e que também precisariam sair da invisibilidade, inclusive no tocante ao mercado de trabalho.

\section{0 trabalho feminino na história recente}

Para que possamos fazer uma análise contundente do trabalho feminino, é fundamental partir da premissa marxista de levantamento dos dados históricos relacionados ao fenômeno. Para Gayle Rubin (2018, p.16), “é apenas submetendo à análise esse 'elemento histórico e moral' que se pode descrever as estruturas da opressão sexual".

O trabalho feminino, muito antes de se iniciar o movimento feminista, tinha relação direta com o ambiente rural. As mulheres eram, em sua maioria, camponesas, não apenas na Europa, mas, sobretudo, nos outros continentes, segundo a historiadora Michelle Perrot (2007, p. 109-110).

$\mathrm{O}$ espaço de atuação feminina estava diretamente relacionado à família e às necessidades do campo e, ainda que os homens deste período fossem, em sua maioria, camponeses como as mulheres, seus papeis não eram os equivalentes, pois havia uma clara divisão do trabalho.

As mulheres eram responsáveis pelo cuidado com a família e com as necessidades domésticas, tais como a alimentação e o vestuário, já que administrava os animais para consumo direto e a horta e, a depender de seu posicionamento entre os familiares, ainda ajudava na 
colheita principal, que era produzida e gerida pelos homens. O excesso da produção, tanto da cultivada na terra quanto os de origem animal, era negociado pelo homem na feira da cidade. (PERROT, 2007, p. 110)

A responsabilidade da mulher, além da alimentação da família, também estava relacionada com a produção do seu vestuário, já que era ela quem fiava e costurava as roupas de todos os membros da família, cuidando dos seus e garantindo um ambiente de conforto no lar. Além disso, este processo de tecelagem, eventualmente, também gerava uma renda extra para a família. (PERROT, 2007, p. 110)

Não há dúvidas de que, neste período, o espaço ocupado pela mulher era, na maior parte do tempo, o espaço privado, uma vez que ela estava, particularmente, restrita ao convívio com os familiares dentro do ambiente doméstico, propiciando a limitação de seu horizonte.

Já, para o homem, a quem era permitida a ida à vila ou ao "comércio" de sua região, abria-se todo um mundo de possibilidades e de acessos, sendo ele o responsável pela negociação não apenas dos bens produzidos por ele, mas também daqueles produzidos pelas mulheres.

Assim, ainda que a percepção fosse a de que o homem era o provedor da família, as mulheres, além de garantir alimentação, limpeza e vestuário, também contribuíam diretamente com produtos que eram negociados por seus maridos ou pais e não recebiam o devido reconhecimento.

Importante ressaltar que os afazeres domésticos ligados à subsistência da família operacionalizados pelas mulheres também contribuíam para o custeio do sustento dos seus, uma vez que poupavam os homens desse encargo, permitindo-lhes dedicar-se ao trabalho com a terra e o comércio.

Tradicionalmente, referimo-nos à economia apenas quando estamos diante da transformação de "elementos do mundo natural" em "objetos de consumo humano" (RUBIN, 2017, p. 17) e deixamos de lado a questão doméstica e a questão da reprodução, tratando-as como algo de menor importância e, portanto, desvalorizadas.

O cuidado com os filhos e com o marido sempre foi considerado como atributos naturais da mulher e, por ser natural, está atrelado à sua função biológica, não sendo necessária a sua remuneração. $\mathrm{O}$ papel da mulher, ainda que invisibilizado, sempre foi fundamental para a manutenção da sociedade pois, consoante Perrot (2007, p. 112), “a dona-de-casa reina sobre a família e os agregados", garantindo a todos o bem-estar necessário para o desenvolvimento das atividades consideradas economicamente valiosas.

Após o início do processo industrial, muitas famílias rurais foram atraídas para as cidades, buscando melhores condições de vida e, portanto, o trabalho feminino também foi 
alterado, não apenas pela transição entre o rural e o urbano, mas também em razão das duas grandes guerras, já que estas retiraram os homens e os jovens de suas casas e as mulheres passaram a administrar sozinhas as suas finanças. (PERROT, 2007, p. 113)

Este desequilíbrio na vida familiar acabou por permitir à mulher ter um vislumbre do espaço público, proporcionando a possibilidade de não mais retornar ao ambiente rural e se inserir na sociedade como alguém que se torna, geração após geração, mais autônoma em relação à sua família.

A inserção feminina, nas escolas e no mercado de trabalho, fora do ambiente de casa, lhes permitiu desejar e buscar outras aspirações e empregos mais relacionados à função intelectual tornaram-se possíveis, deixando de ser a vida no campo a ocupação feminina mais comum. (PERROT, 2007, p. 114)

Quanto ao trabalho feminino no Brasil, ainda que existam semelhanças ao relatado no contexto europeu, a mulher e o mercado de trabalho brasileiro têm especificidades que não podem ser ignoradas, sobretudo em razão da diversidade cultural que se deu com a inserção de diferentes grupos étnicos.

Há três principais etnias e, portanto, três diferentes tradições culturais em território brasileiro que, além de se mesclar em alguns pontos, contribuíram para formatar o conceito de mulher brasileira trabalhadora: as índias, as brancas e as negras ${ }^{1}$.

A mulher indígena não se caracterizava por uma única cultura, mas por um sem número de tribos e sociedades dentre as quais existiam desde mulheres mais submissas a mulheres com grande relação de igualdade com seus pares do sexo masculino. De modo geral, elas cuidavam do cultivo dos gêneros alimentícios, cabendo a tais mulheres, em algumas tribos, o comando da casa e, em outras, o comando cabia aos homens. (TELES, 1999, p. 16)

Há certa semelhança do papel da mulher indígena no Brasil e da europeia, posto que ambas, guardados determinados aspectos culturais, eram responsabilizadas pelo cuidado com a família, especialmente quanto à alimentação e à administração do ambiente doméstico.

Importante mencionar que a chegada dos portugueses, especialmente dos padres jesuítas, provocou um "embranquecimento" da cultura indígena, uma vez que os nativos eram considerados seres irracionais e, portanto, passíveis de controle e transformação para uma cultura mais "civilizada". (TELES, 1999, p. 17)

\footnotetext{
${ }^{1}$ Importante salientar que a menção às etnias que compõem as mulheres brasileiras estão aqui mencionadas apenas com o objetivo que demonstrar que o trabalho feminino em nosso país não se deu de maneira idêntica, na medida em que há uma grande divergência cultural e de classe social entre mulheres brancas, negras e índias. Não há nenhuma intenção de tratar de aprofundamento na história dessas mulheres.
} 
Já as mulheres brancas chegaram mais tardiamente ao Brasil porque, no início, apenas os homens vieram e estes mantinham relações apenas com as escravas índias ou negras, o que possibilitou uma grande miscigenação desde o início da colonização portuguesa. (TELES, 1999, p. 18)

Por esta razão, solicitou-se à coroa portuguesa que enviasse mulheres com o fim de povoar a terra recém colonizada e estas enviadas eram, em sua maioria, órfãs ou prostitutas e, por serem em número reduzido, tornaram-se "mercadoria" rara no Brasil colonial, o que lhes rendia muito ciúme e controle por parte dos maridos.

\begin{abstract}
As informações dessa época são obtidas por meio das narrativas dos poucos estrangeiros que visitavam o Brasil nesse período. Um desses viajantes escreveu que 'os portugueses são de tal forma ciumentos que eles mal lhes (às esposas) permitem ir à missa aos domingos e feriados, não obstante apesar de todas as precauções, são elas quase todas libertinas e encontram meios de escapar à vigilância de seus pais e maridos, expondo-se à crueldade destes últimos, que as matam sem temor de castigo quando descobrem suas intrigas. Os exemplos aqui são tão frequentes que se estimam cerca de 30 mulheres assassinadas pelos maridos em um ano'. (TELES, 1999, p. 18).
\end{abstract}

O que se nota, diante desta narrativa, era que a imposição para a mulher branca se manter no espaço privado se dava por meio de muita violência, donde se extrai o quanto essas mulheres eram tratadas como propriedade por seus pais, maridos e, consequentemente, a percepção de toda a sociedade se espelhava nessa ideia da mulher como um objeto a possuir.

Quanto a isso, Mary Del Priore (2010, p. 28) afirma que as mulheres brancas eram vigiadas de perto até mesmo pelos feitores para que não embarcassem nos navios e retornassem ao Reino sem a devida "autorização", o que corrobora com a afirmação de que seriam, naquele tempo, "mercadoria" escassa e violentamente vigiada no Brasil Colônia.

Esta ideia da mulher como propriedade, segundo Rubin (2017, p. 23-25), relaciona-se a questões vinculadas ao parentesco em tempos considerados primitivos, no qual a mulher, na grande maioria dos povos, foi utilizada como objeto de troca de grande valor entre grupos sociais codependentes.

O valor da mulher estava diretamente vinculado à possibilidade de criação de um vínculo indissolúvel entre duas famílias a partir do nascimento de um herdeiro em comum e, portanto, sua sexualidade estava condicionada diretamente aos interesses do grupo ao qual pertencesse.

A possibilidade de gerar herdeiros, de garantir a continuidade das famílias e, consequentemente, do patrimônio e do poder masculino, dava à mulher um valor material inigualável, razão pela qual houve a necessidade de que esse "bem" fosse devidamente controlado pelos "patriarcas". 
Partindo, portanto, desta premissa fundante do papel feminino dentro das famílias, a mulher sempre teve sua vida sexual e reprodutiva sob o controle de seu pai e de seu marido, enquanto os homens não sofriam qualquer restrição quanto ao seu comportamento sexual, visto que as consequências de suas relações poderiam ser facilmente ignoradas e afastadas.

A mulher negra, por sua vez, também sofria com muita violência perpetuada pelos senhores, tanto em razão do trabalho, quanto em razão de seu papel como concubina e, além disso, as senhoras brancas, que se sentiam ameaçadas por algumas de suas escravas, costumavam vingar-se cruelmente destas. Seu trabalho estava relacionado com a plantação e com os afazeres domésticos ou sexuais, conforme nos relata Maria Amélia Teles (1999, p. 21).

Esse comportamento, apesar de passados quase 500 anos, ainda está manifestamente presente na sociedade brasileira, pois o Brasil é um país com alto índice de mortalidade feminina em razão da sua condição de mulher, conforme narrado na exposição de motivos da Lei do Feminicídio, publicada em 2016, de onde se extrai que "uma mulher morre a cada hora no Brasil” e, desses homicídios, quase a maior parte se dá de forma dolosa e no ambiente familiar, ou seja, em um contexto de violência doméstica (BRASIL, 2016, p. 3).

Além disso, em razão da política escravagista, de separar grupos familiares e misturar os escravos com outros que não falavam o mesmo idioma e sequer possuíam a mesma cultura, havia uma grande dificuldade desses grupos se organizarem ou se apoiarem contra o sistema.

Já no século XVIII, durante a fase do Brasil Colônia, as mulheres brancas e ricas ainda se mantinham confinadas no ambiente privado, e, especialmente nos espaços urbanos, "as trabalhadoras, cativas, forras ou brancas pobres, vendiam, elas também, os seus serviços de lavadeiras, doceiras, rendeiras, prostitutas, parteiras, cozinheiras, etc.” (DEL PRIORE, 2010, p. 69). Disso se denota que a mulher do povo foi inserida no mercado de trabalho em período bem anterior ao da mulher branca e rica, assim como havia ocorrido no continente europeu.

A urbanização favoreceu ao aparecimento de pontos fixos de comércio, os quais eram explorados, em grande número, por mulheres de todas as etnias, especialmente nas periferias das cidades, promovendo a venda de insumos e de bebidas e explorando a prostituição. (DEL PRIORE, 2010, p. 98)

Houve, portanto, assim como já ocorria na Europa, a reprodução da divisão sexual do trabalho em território brasileiro, reforçando a opressão de gênero e de classe e colaborando para a manutenção do patriarcado e do domínio da classe trabalhadora. 


\section{$3 \mathrm{O}$ impacto das ondas do feminismo no mercado de trabalho da mulher brasileira}

A participação da mulher na economia das sociedades ocorreu em todos os lugares, ainda que de maneira invisibilizada e precária. Para Murani e Meron (2016, p. 59), a questão do trabalho feminino não é de fácil compreensão, visto que:

\footnotetext{
Quantas são as mulheres que trabalham, aqui e agora, outrora e alhures? Uma pergunta simples, simplista? Na verdade, não: trata-se de uma questão fundamental, complexa heurística. [...]. Isso porque as mulheres sempre trabalharam, sempre e em toda parte, mas esse trabalho não é necessariamente visível e reconhecido. É o que muito bem lembra Michelle Perrot: as mulheres sempre foram muito ativas, mas desde quando elas passaram a ser remuneradas?
}

O trabalho feminino era desenvolvido, exclusivamente, no ambiente privado e diretamente relacionado ao cuidado e à manutenção das famílias, como o trabalho doméstico, a maternidade e o cuidado lato sensu. É o que chamamos de trabalho reprodutivo.

O mercado de trabalho mudou, não apenas para as mulheres, mas também para os homens, posto que toda a sociedade vem sendo reconfigurada diante da modernidade, alterando nossas perspectivas quanto ao trabalho e quanto à vida social. É natural, portanto, que essa nova configuração impacte o mercado de trabalho, não sendo possível atribuir exclusivamente ao feminismo a responsabilidade por esta renovação.

No entanto, ainda que tenha havido alguma inserção da mulher no mercado de trabalho e até mesmo de legislações que buscam protegê-la, é possível perceber atitudes de discriminação, uma vez que ainda persistem diferenças salariais e segregação horizontal, segundo informa Alice Monteiro de Barros (2008, p. 75).

Para esta autora, ainda existe "a tendência de separar homens e mulheres em determinadas profissões" a partir de suas características 'naturais' legando à mulher as profissões assistenciais e ligadas ao cuidado e as raras proximidades salariais entre os sexos se dão mais pela diminuição do salário do homem e não o contrário. (BARROS, 2008, p. 75)

O primeiro impacto mais forte que ocorreu no mercado de trabalho foi a Revolução Industrial e o aparecimento da burguesia, propiciando uma maior quantidade de oferta de trabalho nas cidades e provocando uma migração das famílias para as regiões urbanas em busca de melhores condições de vida, uma vez que a oferta de trabalho havia aumentado nesses locais e diminuído no ambiente rural.

Entretanto, a transformação do contexto do trabalho para homens e mulheres não se deu de forma equiparada, já que os homens sempre foram maioria entre os trabalhadores e as 
mulheres, desde o início, foram levadas aos postos de trabalho mais precarizados. (MARUANI; MERON, 2016, p. 67)

À luz dos fatos históricos aludidos no primeiro capítulo, os quais denotam a importância dos movimentos sociais, vê-se, com clareza, que o feminismo ajudou a proteger a mulher do avanço do capitalismo, assim como o sindicalismo constituído após a Revolução Industrial propiciou o desenvolvimento de políticas protetivas para o operário.

O mercado de trabalho feminino vem sendo alterado, ainda que a passos lentos. Segundo mostram dados do Censo de 1920 (UNICAMP, 2017, p. 19), a porcentagem de ocupação feminina era de $17 \%$, enquanto a taxa atual verificada pela Pesquisa Nacional por Amostra de Domicílios Contínua (PNAD C), referente ao $4^{\circ}$ trimestre de 2018, estava em torno de 43,9\%, além de elas estarem mais bem preparadas que os homens, já que, entre as trabalhadoras, 24,3\% possuem nível superior e, entre os trabalhadores, o número é de 14,6\% (IBGE, 2018).

Além disso, o rendimento médio, no comparativo entre homens e mulheres, ainda as coloca em uma posição inferior, segundo dados do PNADC, referente ao $3^{\circ}$ trimestre de 2019 (IBGE, 2019), que revelou a média salarial masculina de $\mathrm{R} \$ 2.454,00$ e a da mulher de $\mathrm{R} \$$ 1.923,00, mantendo-se uma diferença salarial de 21,64\%, mesmo que as trabalhadoras já contem com mais formação educacional que os trabalhadores homens.

Apesar da diversificação do trabalho feminino, não mais confinado ao mundo rural e às atividades da casa, a atividade doméstica não deixou de ser sua responsabilidade e essa ideia do cuidado com o lar está refletida em todo o restante do trabalho feminino, ainda que no espaço público.

Este papel determinado às mulheres constrói e orienta toda a sociedade acerca da identidade feminina, gerando para elas uma obrigação de agir e de pensar segundo essas regras, e aos homens uma idealização da feminilidade, que se espraia por todas as funções exercidas pelas mulheres ainda que fora do ambiente doméstico. Na verdade, Perrot (2007, p. 114-115) esclarece que "o caráter doméstico marca todo o trabalho feminino [...]. Isso se espera também da perfeita secretária: que ela coloque flores e que cuide de seu patrão".

A ideia do cuidado como sacerdócio feminino permeia todos os espaços de trabalho, ainda que inserida no contexto do trabalho considerado "produtivo" e, portanto, pode-se notar que a divisão sexual do trabalho ainda persiste, já que às mulheres são relacionados os trabalhos mais sensíveis e delicados e aos homens os pesados e agressivos.

Essa percepção, fortemente desenvolvida pelo feminismo marxista, alimentou os movimentos sociais feministas brasileiros, sobretudo os movimentos sindicais nos quais as 
mulheres estavam presentes, ainda que com grande dificuldade de protagonismo em razão das questões relacionadas ao gênero. (GIULANI, 2017, p. 642-644)

Após a Segunda Guerra e a adoção do Estado de Bem Estar Social, por boa parte dos países da Europa e Estados Unidos, essa nova perspectiva ampliou a percepção do salário de família, cujo provedor era o homem, como o mais importante para o sustento dos grupos familiares, sem dar qualquer valor ao salário feminino, caso a mulher conseguisse autorização para "trabalhar fora", ou, e talvez, o mais grave dos problemas, a completa desvalorização do trabalho reprodutivo e, por consequência, do trabalho feminino. (FRASER, 2016, p. 40)

Essa desvalorização, inserindo sempre a mulher em um contexto de trabalho menos importante e menos valorizado, tem reflexos claros até os dias atuais, uma vez que são elas que realizam a maior parte dos trabalhos mal remunerados, sobretudo a mulher negra e pobre.

As mulheres brasileiras foram protagonistas na luta por melhores condições de trabalho. Foram as trabalhadoras da indústria têxtil de São Paulo que, em 1907, iniciaram um movimento grevista que se tornaria a primeira greve geral do Brasil, atingindo outros setores da economia e chegando, posteriormente, a outros estados. (ALVIN, 1983, p. 76)

Entretanto, algum avanço jurídico se deu em matéria de trabalho feminino, com o reconhecimento nas Constituições brasileiras que, desde 1934, reconhecem a obrigatoriedade do pagamento de salários equiparado entre homens e mulheres, culminando a consagração desse direito no art. $7^{\circ}$, incisos XX e XXX, da atual Constituição da República (1988) e a inclusão na CLT, em 1999, da proibição de inclusão de requisitos relativos ao gênero em anúncios de emprego, em seu art. 373-A e seus incisos.

O mercado de trabalho brasileiro, segundo Guimarães e Brito (2016, p. 72), não é mais dominado pelos homens, ou seja, houve um impacto real no mundo do trabalho brasileiro, pois:

\footnotetext{
Em 1960, quase oito em cada dez homens aptos a trabalhar ali buscavam os meios de sobreviver, contra menos de duas em cada dez mulheres. Nesses cinquenta anos, a incorporação feminina à população economicamente ativa (IPEA) quase quadruplicou (a taxa de atividade feminina alcançou 0,52). Distinto foi o padrão de engajamento dos homens: elevado já no início do período (taxa de atividade de 0,77), declinou nas últimas duas décadas (0,70 em 2010). A convergência entre o engajamento de homens e mulheres sustentou-se num movimento impulsionado pela célere mercantilização do trabalho delas.
}

Mirla Cisne (2014, p. 17) afirma que, embora tenha havido alguma inserção da mulher no mercado de trabalho, esta não a teria retirado da posição de maior vulnerabilidade, uma vez que, dentre os pobres do mundo, $70 \%$ são mulheres, bem como realizam, ainda, a maior parte do trabalho precarizado e, exatamente pela função que comumente exercem, acabam por sofrer maior impacto de políticas públicas ineficazes. 
Podemos perceber esse impacto mais direcionado à mulher, corroborando com a fala de Mirla Cisne, quando analisamos a taxa de pessoas desocupadas no Brasil na qual se verifica que as mulheres são 53,3\% (IBGE, 2019), isso demonstra que as mulheres são muito mais afetadas pelo desemprego que os homens, sobretudo em períodos de crise econômica como a que atravessamos atualmente.

O que se percebe, diante deste quadro, é que a alteração sofrida no mercado de trabalho e a inserção massiva da mulher não estão diretamente ligadas à sua libertação do patriarcado ou à sua independência. O que ocorreu está muito mais relacionado à apropriação da força de trabalho feminina pelo mercado capitalista, já que sua precariedade poderia trazer ainda mais acumulação de capital.

Segundo Engels (1981, p. 10), a sociedade anterior ao capitalismo se baseava nos laços sanguíneos e, atualmente, estaríamos baseados nas classes sociais. Essa mudança não se operou em razão de qualquer luta feminista ou de direitos, ela ocorreu pelo desenvolvimento do capitalismo que colocou os seres sociais em posições diversas, e a mulher não foi excluída deste processo.

A inclusão da mulher, em postos anteriores ocupados apenas pelos homens e, de certa maneira, relacionados ao espaço público, deu-lhes algumas novas percepções acerca de seu papel e do quanto essa desigualdade era perversa com seu gênero. Esta mudança social, sem nenhuma intenção, permitiu às mulheres diagnosticar, com mais clareza, quais seriam as origens de sua opressão e sofrimento, propiciando um início de movimento que tem o objetivo de mudar a cultura do patriarcado.

Na visão de Fraser (2016, p. 45), fica claro que houve uma coincidência entre a segunda onda do movimento feminista e a consagração das ideias neoliberais, impondo uma agenda anti-keynesiana e impondo maiores restrições. Além disso, foram os países ditos de Terceiro Mundo e, portanto, os grupos sociais mais hipossuficientes, dentre eles as mulheres, os que mais sofreram com as novas políticas.

Foi nesse terreno fértil, marcado pelas ideias neoliberais, que foi sido possível o florescimento da segunda onda do feminismo, "atraindo partidários de todas as etnias, nacionalidades e ideologias políticas, as ideias feministas penetraram em todos os cantos escondidos da vida social e transformaram a ideia que todos os afetados tinham de si mesmos" (FRASER, 2016, p. 45).

Para que haja, de fato, a igualdade material tão almejada entre homens e mulheres, há que se desenvolver principalmente uma mudança cultural, redefinindo seus possíveis papéis, seja por meio de políticas públicas inclusivas, seja por meio dos movimentos sociais. 
O movimento feminista, iniciado tanto tempo atrás, trouxe muita mudança para a vida da mulher em sociedade, já que, na maioria dos países ocidentais, o voto é permitido, o estudo é até estimulado e a inserção no mercado de trabalho se deu, ainda que de forma lenta e gradual, de maneira a permitir alguma independência feminina, uma vez que as mulheres, agora, "penetram em um mundo edificado pelos homens, num momento histórico em que o fator biológico ainda era considerado essencial, daí a dificuldade de se aceitar a influência sociocultural na formação do gênero" (BARROS, 2008, p. 69).

O problema é que essa percepção de melhora na vida da mulher não pode fundamentar um recrudescimento do movimento, pois apenas alguns direitos foram duramente conquistados, mas a cultura ainda está extremamente preservada no imaginário popular. Ainda se questiona essa independência da mulher, ainda lhe é atribuído o trabalho reprodutivo, ainda lhe cobram o cuidado como um atributo natural do ser feminino.

Segundo Fraser (2016, p. 46), a situação pode ser ainda mais grave, na medida em que as recentes lutas pelo reconhecimento, para onde a academia se voltou, e que teriam sido estimuladas pela política neoliberal, afastam o movimento feminista da luta por igualdade, à medida que descaracterizam os ideais da segunda onda.

Ademais, sendo ainda consideradas responsáveis pelo trabalho doméstico, “donas de casa" têm seu trabalho explorado gratuitamente e sem qualquer reconhecimento, uma vez que estariam apenas “cumprindo com suas obrigações”. Segundo a ONU Mulheres Brasil (2017), o trabalho doméstico não remunerado seria responsável por até 39\% do PIB:

O valor do trabalho de cozinhar, limpar, cuidado de crianças e dar atenção a pessoas idosas - tarefas que a economia depende - representa entre 10 e $39 \%$ do PIB. Pode pesar mais na economia de um país do que pesam a indústria manufatureira ou a do comércio.

Dessa forma, ainda há muito a ser feito, há muita luta pela frente e muito enfrentamento necessário para que possamos, finalmente, acabar com a divisão sexual do trabalho e, finalmente, atingirmos a igualdade material tão prometida pela contemporaneidade, mas fortemente ignorada pelos movimentos feministas da atualidade.

Buscando responder, portanto, à problemática proposta neste artigo, não podemos ignorar a grande mudança ocorrida no mercado de trabalho feminino nos últimos dois séculos, não apenas para as mulheres brancas e ricas, mas também para as mulheres negras, índias ou pobres no Brasil.

Contudo, a onda neoliberal tem, constantemente, alterado o mercado de trabalho e até mesmo alguns aspectos da luta feminista, influenciando diretamente na ressignificação do 
movimento para fazer crer na necessidade de uma mulher livre e autônoma, mas com salários cada vez mais baixos e menos investimento do Estado em políticas públicas (FRASER, 2016, p. 48).

A terceira onda do feminismo, mais voltada à questão do reconhecimento da diferença e da ressignificação do gênero como uma categoria de análise, por outro lado, caminha no sentido, como já sugeria Fraser, de dividir a luta feminista e, portanto, enfraquecer o movimento.

Com efeito, ainda que sejam fundamentais a reflexão e a inclusão de outras minorias no debate inclusivo iniciado pelo movimento feminista, em termos de mercado de trabalho, categoria analisada neste trabalho, o que se nota é um aumento da percepção de liberdade e autonomia do ser humano em total harmonia com os ideais neoliberais e, consequentemente, menos protetivos da coletividade.

\section{Considerações finais}

Não há dúvidas de que o movimento feminista vem provocando grandes reflexões quanto às relações sociais de sexo no decorrer dos últimos 200 anos. Ademais, a inserção da mulher, no espaço público, vem ocorrendo, ainda que a passos lentos e em momentos e formas diferentes a depender da cultura local, já que, em alguns países, os avanços são quase imperceptíveis e, em outros, já se nota um considerável avanço na igualdade entre homens e mulheres.

Houve conquistas como o direito ao voto, o divórcio, a independência financeira de algumas, a simples ideia de ser "senhora" de suas próprias vontades e de seu próprio corpo ganha cada vez mais contorno na sociedade atual, sobretudo em países desenvolvidos e com políticas públicas afirmativas que se implementaram com maior engajamento.

Em países como o Brasil, ainda há muito a ser feito. No entanto, também houve melhoras quanto à inserção da mulher no mercado de trabalho, especialmente das mulheres brancas e de classe média e alta, afinal, a precarização do trabalho feminino ainda gera consequências graves à formalização do trabalho de muitas mulheres, sobretudo das negras, das pardas e as de classe baixa.

É importante mencionar que essa inserção da mulher no mercado de trabalho está muito mais relacionada à revolução industrial e à necessidade do capital de aumentar o número de trabalhadores e a um custo cada vez mais reduzido, afinal as mulheres continuam a ter salários inferiores aos dos homens e estão inseridas nos postos de trabalho mais precarizados. 
Pode-se dizer, contudo, que houve algum impacto do movimento feminista no mercado de trabalho da mulher no Brasil, especialmente a partir da segunda onda, que tratava, essencialmente, da inserção de pautas como classe e raça no contexto feminista, o que nos leva a crer em seu maior impacto para a conquista de mais igualdade para a mulher, propiciando maiores avanços no futuro.

Além disso, a terceira onda, com seu conceito de fluidez do gênero, pode trazer ainda mais questionamentos dentro do ambiente do trabalho, uma vez que busca incluir outras minorias que não se encaixam, necessariamente, nos conceitos clássicos de homem e mulher. Todos os cidadãos pertencentes aos grupos LGBTI+ estão buscando sua "desinvisibilização" por este movimento e trazendo suas pautas para o centro do debate na sociedade.

É possível que este novo foco, assim como já vem ocorrendo com outras parcelas minoritárias da população, contribua para a diminuição da discriminação com tais grupos e a consequente inserção dos mesmos nos ambientes laborais.

No entanto, a perspectiva do reconhecimento relacionado à ressignificação do conceito de gênero aproxima o movimento feminista de sua pauta mais liberal, contrariando a luta da segunda onda que buscava igualdade, sobretudo, material, para as mulheres e essa pauta precisa ser revisitada, sob pena de se perder entre tantas questões identitárias.

\section{Referências}

ALVIN, Zuleika M. F. A participação política da mulher no início da industrialização em São Paulo. Revista de História (114), São Paulo, 1983, pp. 61-84. Disponível em: http://www.revistas.usp.br/revhistoria/article/view/62062/64898. Acesso em: 19 fev. 2019.

BARROS, Alice Monteiro de. Cidadania, relações de gênero e relações de trabalho. Revista do Tribunal Regional do Trabalho da $3^{\text {a }}$ Região, Belo Horizonte, v. 47, n. 77, 2008, pp. 67 83.

CISNE, Mirla. Feminismo e consciência de classe no Brasil. São Paulo: Cortez, 2014.

DEL PRIORE, Mary. Uma breve história do Brasil. São Paulo: Ed. Planeta do Brasil, 2010.

DUARTE, Constância Lima. Feminismo e literatura no Brasil. Estudos Avançados, São Paulo, v. 17, n. 49, p. 151-172, Dec. 2003. Disponível em: http://www.scielo.br/scielo.php?script=sci_arttext\&pid=S010340142003000300010\&lng=en\&nrm=iso. Acesso em: 05 fev. 2020. http://dx.doi.org/10.1590/S0103-40142003000300010.

ENGELS, Friedrich. Caracteres da monogamia. In: ENGELS, F; MARX, K.; LÊNIN, V. Sobre a mulher. 3. ed. São Paulo: Global, 1981, pp. 22-27. Coleção Bases, v. 17. 
ENGELS, Friedrich. O Materialismo Histórico e a Família. In: ENGELS, F; MARX, K.; FRASER, Nancy. O feminismo, o capitalismo e a astúcia da história. Revista Outubro (26), 2016, pp.31-56. Disponível em: http://outubrorevista.com.br/wpcontent/uploads/2016/07/02_Nancy-Fraser.pdf. Acesso em: 15 set. 2018.

GIULANI, Paola Cappellin. Os movimentos de trabalhadoras e a sociedade brasileira. In: PRIORE, Mary Del (Org.). História das mulheres no Brasil. 10. ed. 5. reimp. São Paulo: Contexto, 2017.

GONCALVES, Eliane; PINTO, Joana Plaza. Reflexões e problemas da "transmissão" intergeracional no feminismo brasileiro. Cadernos Pagu (36), Campinas, 2011, pp. 25-46. Disponível em: http://www.scielo.br/scielo.php?script=sci_arttext\& pid=S0104$83332011000100003 \& \operatorname{lng}=$ pt\&nrm=isso-. Acesso em: 15 set. 2018.

GUIMARÃES, Nadya Araújo; BRITO, Murillo Marschner Alves de Brito. Mercantilização no feminino: a visibilidade do trabalho das mulheres no Brasil. In: ABREU, Alice Rangel de Paiva; HIRATA, Helena; LOMBARDI, Maria Rosa. Gênero e trabalho no Brasil: perspectivas interseccionais. São Paulo: Boitempo, 2016.

IBGE. Indicadores IBGE: pesquisa nacional por amostra de domicílios contínua. Rio de Janeiro: IBGE, Coordenação de Trabalho e Rendimento, 2018. Disponível em: http://www.ibge.gov.br/Home/estatística/indicadores/trabalhoerendimento/pnad_continua/def ault.shtm. Acesso em: 21 mar. 2019.

IBGE. Indicadores IBGE: pesquisa nacional por amostra de domicílios contínua. Rio de Janeiro: IBGE - Coordenação de Trabalho e Rendimento, 2019. Disponível em: https://www.ibge.gov.br/estatisticas/sociais/trabalho/9171-pesquisa-nacional-por-amostra-dedomicilios-continua-mensal.html?=\&t=series-historicas. Acesso em: 12 fev. 2020.

KERGOAT, Danièle. O cuidado e a imbricação das relações sociais. In: ABREU, Alice Rangel de Paiva; HIRATA, Helena; LOMBARDI, Maria Rosa. Gênero e trabalho no Brasil: perspectivas interseccionais. São Paulo: Boitempo, 2016.

LÊNIN, V. Sobre a mulher. 3. ed. São Paulo: Global, 1981. Coleção Bases, v. 17.

MACHADO, Michelle Maria Costa. A importância da condição humana na promoção do direito fundamental de proteção ao trabalho da mulher no ordenamento jurídico brasileiro. Direito Unifacs: revista eletrônica mensal (212), Salvador, 2018, pp. 1-26. Disponível em: https://revistas.unifacs.br/index.php/redu/article/viewFile/5236/3352. Acesso em: 27 fev. 2019.

MURANI, Margaret; MERON, Monique. Como contar o trabalho das mulheres? In: ABREU, Alice Rangel de Paiva; HIRATA, Helena; LOMBARDI, Maria Rosa. Gênero e trabalho no Brasil: perspectivas interseccionais. São Paulo: Boitempo, 2016.

NARVAZ. Martha Giudice; KOLLER, Sílvia Helena. Metodologias feministas e estudos de gênero: articulando pesquisa, clínica e política. Psicologia em estudo, Maringá, v. 11, n. 3 , 2006, pp. 647-654. 
ONU. ONU MULHERES BRASIL. Trabalho de cuidados oscila entre 10 e 39\% do PIB de países, considera ONU Mulheres. Brasília: Onu Mulheres Brasil, 2017. Disponível em: http://www.onumulheres.org.br/noticias/trabalho-de-cuidados-oscila-entre-10-e-39-do-pib-depaises/. Acesso em: 27 fev. 2019.

PERROT, Michelle. Minha história das mulheres. Trad. Angela M. S. Correa. São Paulo: Contexto, 2007.

RUBIN, Gayle. Políticas do sexo. Trad. Jamille Pinheiro Dias. São Paulo: Ubu Editora, 2017.

SCOTT, Joan W. O enigma da igualdade. Revista Estudos Feministas, Florianópolis, v. 13, n. 1, p. 11-30, abr. 2005. Disponível em:

http://scielo.br/scielo.php?script=sci_arttext\&pid=S0104-

026X2005000100002\&Ing=em\&nrm=iso. Acesso em: 10 fev. 2020.

SIQUEIRA, Carolina Bastos; BUSSINGER, Elda Coelho de Azevedo. Estruturalismo e pósestruturalismo: uma análise comparativa das contribuições teóricas feministas de Simone de Beauvoir e Judith Butler. Anais do XI Seminário Internacional Fazendo Gênero [recurso eletrônico]: 13th. Women's Worlds Congress (Org. Jair Zandoná, Ana Maria Veiga e Cláudia Nichnig). Florianópolis: UFSC, 2018. Disponível em: http://www.wwc2017.eventos.dype.com.br/resources/anais/1499196025_ARQUIVO_Artigo13MundodaMulheres.pdf. Acesso em: 10 fev. 2020.

TELES, Maria Amélia de Almeida. Breve história do feminismo no Brasil. São Paulo: Brasiliense, 1999. (Coleção tudo é história: 145)

UNICAMP. Mulheres: mundo do trabalho e autonomia econômica (Cadernos de Formação). São Paulo, Instituto de Economia da UNICAMP e Equipe do Centro de Estudos Sindicais e Economia do Trabalho - CESIT/IE, 2017. Disponível em: http://www.eco.unicamp.br/images/arquivos/Caderno-3-web.pdf. Acesso em: 21 mar. 2019.

WOLLSTONECRAFT, Mary. Reivindicação do direito das mulheres. Trad. Ivania Pocinho Motta. São Paulo: Boitempo: Iskra, 2016. Livro digital. 